\title{
NEWS: ATSI Education Drafts Taking Shape
}

Draft teaching units for a comprehensive Curriculum Corporation project developing Aboriginal and Torres Strait Islander Studies teaching and learning materials have recently been completed and are being distributed in a national consultation process.

According to Senior Policy Officer (Social and Cultural Studies) Richard Dunlop, who is managing the project, the teaching units are a 'national first'.

The final draft units will be developed by July 1995, and will be published by the Curriculum Corporation early next year, he said.

The draft units, comprising some 200 pages, are based on the National Statement and Profile in Studies of Society and Environment and have been written by indigenous authors who all have considerable classroom experience. They are aimed at all Year 1 - 10 Australian Students.

The authors are Judy Ketchell, Liz Connor, Steve Smith, Leonie Coghill, Kaye Price, Darcel Moyle and Karen Martin.

Dr Dunlop noted that the project was the result of a successful Department of Education tender for a Curriculum Corporation grant of $\$ 65,000$.

Further information may beobtained by contacting Dr Richard Dunlop, SPO Social and Cultural Studies, Floor 19 Education House, PO Box 33, AlRERT STREET Q 4002 Ph: (07) 2370887 or Fax: (07) 2100227.

DrDunlopalso provided answers to somecommon questions associated with the project.

\section{Q. Why is it labelled Stage One?}

A: It is labelled Stage One because Aboriginal Studies and Torres Strait Islander Studies are 'secured' in the learning area of Studies of Society and Environment, and this learning area is being dealt with first. Subject to the successful completion of the SSE material, similar materials are likely to be developed in other learning areas.

Q. What exactly are the project's aims?

A: The major aims of the project are:

(a) To produce curriculum materials in Aboriginal Studies and Torres Strait Islander Studies which relate to the SOSE National Statement and Profile and which are aimed at primary and secondary teachers (Years K10);

(b) To produce a book of approx. 160 pages, which includes up to 5-10 pages of guidelines; teaching units for lower primary (Band A), upper primary (Band $B$ ), and junior - middle secondary (Band C); student work samples; ideas for assessment and reporting; a description of recommended theoretical and practical teaching resources; acknowledgements and lists of sources.

$Q$. Are there set timelines for the project?

A: Yes. Curriculum Corporation negotiated the following milestones for the project with the Department of Education:

July 1994 Work commences

31 January 1995 Complete first draft to Curriculum Corp

31 July 1995 Submission of final manuscript to Curriculum Corp 
Aug-Oct 1995 Editing and checking with authors

April 1996 Publication

\section{$Q:$ Why are there so many writers?}

A: Because of the short timelines for achieving the aims, it was decided that they would be best attained by dividing the larger task into its component parts and drawing upon a number of writers throughout the state, and one from interstate to simultaneously develop the material. There were other features of the project which made this a sensible approach. There was a need to have Aboriginal writers for the majority of the Aboriginal Studies component, and Torres Strait Islander writers for the majority of the Torres Strait Islander Studies component. Also, various elements required writers with different skills and backgrounds, for example, one individual may have been excellent to write the guidelines but not in a position to develop a teaching unit for lower primary students.

\section{Q: On what basis were the writers selected?}

A: The writers were selected on the grounds that they must:

- be Indigenous;

- be drawn from locations throughout the State (and interstate if necessary), and represent a range of community settings;

- have curriculum development expertise;

- have a basic awareness of national curriculum developments, and have the capacity to rapidly gain this knowledge over the course of the project; and

- have proven achievements when working under pressure and reliability in meeting deadlines.
$Q:$ What comments have there been so far on the writers' work?

A: The materials are in draft form only at this stage, and are yet to be subject to a national consultation process. To date, the writers have had the benefit of exchanging their ideas during two workshops which were conducted in September and December, involving representatives of the Department, Curriculum Corporation and a number of 'critical friends' (frequently with national reputations for their expertise in Aboriginal Studies and/or Torres Strait Islander Studies). Until the national consultation process is completed, however, the views expressed by the writers in the draft material do not necessarily reflect the policies of the Queensland Department of Education, Curriculum Corporation or policies developed nationally by other organisations.

Q: How have the writers come to grips with the diversity of indigenous cultures?

A: The principles and guidelines and each of the units recognise the enormous diversity of indigenouscultures within Australia. Specifically, different teaching units have been developed to address the distinct cultural differences of Torres Strait Islander people and Aboriginal people. The writers themselves are currently living and working in a diversity of settings, ranging from primary schools in isolated or island communities to secondary schools in heterogenous urban contexts. While many of the units focus on a particular place, the intention is that the units provide models for other teachers to adapt in order to suit the demands of their own location, reflect historical and contemporary issues, and other factors such as the availability of resources and the needs and interests of students. Throughout, teachers are particularly urged to 
consult members of the local school community to determine their preferences and assess their capacity to contribute to the success of programs of work in Aboriginal Studies and Torres Strait Islander Studies.
Editor's Note: This article originally appeared in Education Views on March 24 1995, p. 13 and is reprinted with permission of the Public and Media Relations Branch of the Queensland Department of Education.

\section{NEWS: ATSI Education on the Agenda}

\section{From the DG's Desk}

Frank Peach, Director-General of Education

Why did I make education of Aboriginal and Torres Strait Islander children one of the three major priorities for our Department?

Most of my teaching career was spent in schools - Cairns, Bamaga, Inala - with large numbers of Aboriginal and Torres Strait Islander students, so I know at first hand the challenges facing both the staff in schools and the students and their families.

I am also aware of the improvements that have occurred over the last 25 years; however, there is no doubt that these improvements are in selective areas. Most of our Aboriginal and Torres Strait Islander students and their families are, as a group, significantly disadvantaged in our education system.

As a nation we are moving towards a process of reconciliation; as teachers and leaders we must reflect this through action in ourschools - action that must above all bring meaningful improvements in student learning and achievement.

Let us look at and celebrate the improvements that have occurred.

ATSI student retention to Year 12 has grown from around 2 per cent in 1970 to more than 40 per cent in 1995; the number of Aboriginal and Torres Strait Islander teachers has grown from five in 1975 to 170 in 1995; and Aboriginal and Torres Strait Islander education workers in our schools (counsellors, aides, support and ancillary staff) have increased from a handful in 1975 to around 190 in 1995.

The number of Aboriginal and Torres Strait Islander senior officers in one department has grown from nil in 1975 to six in 1995.

Our Department has assumed the responsibility for the provision of education in all Aboriginal Communities and Torres Strait Islands; parents have been made to feel welcome in schools and they have become more involved.

We have developed a range of curriculum materials and teaching/learning approaches, established the Statewide Aboriginal and Torres Strait Islander Support Centre and included an Aboriginal and Torres Strait Islander sub-program in our departmental program structure. 